\title{
A biophysical elucidation for less toxicity of Agglutinin than Abrin-a from the Seeds of Abrus Precatorius in consequence of crystal structure
}

\author{
Jack Cheng ${ }^{1}$, Tian-Huey Lu*1, Chao-Lin Liu² and Jung-Yaw Lin³
}

\begin{abstract}
X-ray crystal structure determination of agglutinin from abrus precatorius in Taiwan is presented. The crystal structure of agglutinin, a type II ribosome-inactivating protein (RIP) from the seeds of Abrus precatorius in Taiwan, has been determined from a novel crystalline form by the molecular replacement method using the coordinates of abrin-a as the template. The structure has space group P4,2,2 with $Z=8$, and been refined at $2.6 \AA$ to $R$-factor of $20.4 \%$. The rootmean-square deviations of bond lengths and angles from the standard values are $0.009 \AA$ and $1.3^{\circ}$. Primary, secondary, tertiary and quaternary structures of agglutinin have been described and compared with those of abrin-a to a certain extent. In subsequent docking research, we found that Asn200 of abrin-a may form a critical hydrogen bond with G4323 of 28SRNA, while corresponding Pro199 of agglutinin is a kink hydrophobic residue bound with the cleft in a more compact complementary relationship. This may explain the lower toxicity of agglutinin than abrin-a, despite of similarity in secondary structure and the activity cleft of two RIPs.
\end{abstract}

\section{Background}

Ribosome inactivating proteins (RIPs) are enzymes that can inactivate ribosomes. The molecular mechanism of inhibitory effect on protein synthesis has been shown that RIPs act as a RNA N-glycosidase hydrolyzing the C$\mathrm{N}$ glycosidic bond of the adenosine residue at position 4324 in rat $28 \mathrm{~S}$ rRNA $[1,2]$. They can cleave the synthetic RNA structure having a short double-helical stem and a loop containing a centered GAGA sequence, the first A being the cleavage site [3]. The depurination inactivates the ribosomes for binding to elongation factor 2 catalyzing GTP hydrolysis and translocation of peptidyl-tRNA to the P site [4], with a consequence inhibiting the protein synthesis. There are three categories of RIPs according to the physical composition and characteristics. Most commonly RIPs are type I RIPs, only single polypeptide chain proteins composed of the toxophoric A subunit with a molecular mass around $30 \mathrm{kDa}$ [5-8] such as curcin [9] and trichomislin [10]. Some are type II RIPs consisting of two types of polypeptide subunits, A chain of homolo-

*Correspondence: thlu@phys.nthu.edu.tw

1 Department of Physics, National Tsing Hua University, Hsinchu 30013, Taiwan Full list of author information is available at the end of the article gous and functionally similar to type I RIPs and B chain with a galactose-specific lectin domain that binds to cell surfaces, such as ricin [11] abrin and abrus agglutinin (AAG) [12]. A chain and B chain are from one gene and link through disulfide bond after post-translation modification [13]. Type III RIPs are derived from inactive proprotein and activated after proteolysis [14]. The mature type III RIPs are two polypeptide subunits acting as an $\mathrm{N}$ glycosidase jointly.

Various RIPs can be isolated from the same plants $[15,16]$. Some type II RIPs have been isolated from the beans of the tropical and subtropical leguminous plant Abrus precatorius, jequirity. They are lectins and have an inhibitory effect on the growth of experimental animal tumors $[17,18]$. They can be classified as abrins and AAG by oligomerization. Abrins are potent toxic heterodimeric glycoproteins with an LD50 of $20 \mu \mathrm{g} / \mathrm{kg}$ body weight; while AAG is a relatively less toxic heterotetrameric glycoprotein of which the LD50 is $5 \mathrm{mg} / \mathrm{kg}$ body weight [12]. But their therapeutics indexes are similar [18].

The primary structures of abrin-a and AAG were determined [19-21]. AAG had high homology to the extremely 
toxic ABRa, with $44(8.0 \%)$ similar amino acid residues and $382(69.8 \%)$ invariant amino acid residues. In the A chain of AAG, the 13 amino acid residues with catalytic function among RIPs were completely conserved [21]. The cDNAs of the RIPs isolated from Abrus precatorius have been cloned and their A chains were expressed in Escherichia. coli [21-23]. The amino acid residues at proposed active sites and Pro199 of AAG, which corresponding to Asn200 of abrin-a, were analyzed with site-directed mutagenesis for studying the structure and function of these RIPs $[21,23,24]$. And the results showed that Pro199 in A- (or C-) chain of AAG impair the activity of protein synthesis inhibition because of steric hindrance [21]. According to the biochemical experiments, the mutation of Asn200 on abrin a-chain to Pro200 dramatically decreases the activity than other kind of mutation, including those residues without side-chain, such as Gly $[23,24]$. These peculiar results motivate us to crystallize AAG, and make comparison with abrin, since both contains almost identical active pocket, and most important of all, different at Asn200 (the corresponding residue is on AAG Pro199). Bagaria et al., [25] reported a $3.5 \AA$ Xray crystal structure, and proposed the less toxic nature is because of the fewer interactions involved with the substrate adenine.

Bagaria et al., [25] assigned their low resolution of AAG crystal to belong to the space group of $\mathrm{P}_{2} 2_{1} 2$, instead of our present and previous $\mathrm{P}_{1} 2_{1} 2$ [26], to analyze the crystal structure based on a mixture of indigenous and alien data. They crystallized their Indian AAG material in a condition similar to, but different from ours $[25,26]$. Strange to us, they did not determine their own Indian AAG amino acid sequence, but adopted the Taiwanese primary structure $[21,25]$. Indian AAG molecular packing may be different from our Taiwanese that could manifest itself some way in different space group. Although they published the controversial paper of $60 \mathrm{kDa}$ structure in advance [25], this detail worthwhile work of more complicated and precise $120 \mathrm{kDa}$ heterotetramer agglutinin structure spurs the continuous study of our last research [26].

\section{Methods}

\section{Purification}

AAG was isolated from the kernels of Abrus precatorius seeds by chromatographies on a Sepharose 6B column and a Sephadex G-100 column as described previously [12]. The flow rate of chromatography was $20 \mathrm{ml} / \mathrm{hr}$ and protein concentration was determined by the bicinchonic acid method [27]. The kernels of $200 \mathrm{~g}$ were soaked in 5\% cold acetic acid of $1 \mathrm{~L}$ overnight and homogenized. After centrifuging at $10,000 \mathrm{~g}$ at $4^{\circ} \mathrm{C}$ for $15 \mathrm{mins}$, the supernatant was collected for subsequently subjecting to the ammonium sulfate fraction between 35 and 90 and then centrifuging at $10,000 \mathrm{~g}$ at $4{ }^{\circ} \mathrm{C}$ for $20 \mathrm{mins}$. The precipitate was collected for dialysis against cold $10 \mathrm{mM}$ sodium phosphate buffer, $\mathrm{pH} 8$ at $4^{\circ} \mathrm{C}$. The dialysis buffer was changed every $8 \mathrm{hrs}$ for more than 2 days. The supernatant of dialysate was centrifuged at $17,800 \mathrm{~g}$ at $4^{\circ} \mathrm{C}$ for 20 mins and then applied on a Sepharose 6B affinity column $(3.0 \times 50 \mathrm{~cm})$ pre-equilibrated and washed with $10 \mathrm{mM}$ sodium phosphate buffer, $\mathrm{pH} 8$. The eluent constiting of abrins and AAG were obtained with the elution buffer, the wash buffer containing $100 \mathrm{mM}$ D-galactose. Then the precipitate was obtained from the eluent subjected to $90 \%$ ammonium sulfate and dialyzed and centrifuged as mentioned above. The supernatant was loaded onto gel filtration on Sephadex G-100 column $(2.2 \times 100 \mathrm{~cm})$ with $10 \mathrm{mM}$ sodium phosphate buffer, $\mathrm{pH}$ 8. Two major peaks can be observed and the fractions of AAG, corresponding to the first peak, were pooled and lyophilized.

\section{Crystallization}

The formula for crystallization was described in our previous paper [26]. Crystals suitable for X-ray analysis were obtained by the sitting drop vapor-diffusion method at room temperature (297 (2) K) [28]. $8 \mu$ of protein solution at a concentration of $10 \mathrm{mg} / \mathrm{ml}$ prepared from lyophilized protein was mixed with $8 \mu$ of reservoir solution containing PEG 8000; the precipitant condition was 0.1 $\mathrm{M}$ Tris $\mathrm{pH} 7.5$ with $6.5 \%$ PEG 8000 plus $1 \%$ sodium azide and crystals appeared after nearly four months.

\section{Data Collection}

X-ray Data were collected with a crystal of dimensions $0.30 \times 0.30 \times 0.25 \mathrm{~mm}$ that was mounted in a cryo-loop manufactured by Hampton Research. After immersed in the cryo-protectant of $20 \%$ glycerol and $80 \%$ mother liquor for several seconds, the cryo-loop was mounted on goniometer head inside liquid nitrogen stream at $100 \mathrm{~K}$. $\mathrm{X}$-ray diffraction was measured with CCD (ADSC Quantum-Q4R CCD Area Detector), on 1 D synchrotron radiation X-ray (SPring-8 Taiwan Contract Beam-line BL12B2 of NSRRC). The crystal-to-detector distance was $215 \mathrm{~mm}$. The space group and unit-cell parameters were determined from the well resolved diffraction spots. The data were processed using the programs HKL2000 [29]. The agglutinin crystal belongs to the tetragonal system, with unit-cell parameters $\mathrm{a}=\mathrm{b}=137.05, \mathrm{c}=214.42 \AA \mathrm{n}, \mathrm{V}$ $=4.0275 \times 10^{6} \AA^{3}, \mathrm{Z}=8$. A $99.1 \%$ complete dataset to 2.47 $\AA$ A resolution of 73,976 unique reflections was collected with averaged $R_{\text {sym }}$ of $7.2 \%$, averaged $\chi^{2}$ of 1.153 , averaged $\mathrm{I} / \sigma$ of 11.89 , and redundancy of 4.1 .

\section{Determination of space group and initial phase}

The systematic absences, $1=4 \mathrm{n}+1,2,3$ for 001 reflections, and $h=2 n+1$ for $h 00$ reflections, indicate that 
there are two possible space groups, namely $\mathrm{P}_{4} 2_{1} 2$ or $\mathrm{P}_{3}{ }_{3}{ }_{1}$. The ambiguity of space group was solved together with the initial phase problem by molecular replacement method using version 1.1 of CNS program [30] with the coordinates of abrin-a [31] as model. An X-ray diffraction data shell from 4 to $15 \AA$ was used for the calculation of the cross rotation function with CNS program [32]. The highest two were corresponding to a rotation of the model by the rotation angel of $\theta 1=37.9 \mathrm{E}, \theta 2=39.6 \mathrm{E}, \theta 3$ $=342.1 \mathrm{E}$, and $\theta 1=358.1 \mathrm{E}, \theta 2=-0.5 \mathrm{E}, \theta 3=2.4 \mathrm{E}$ in the space group of $\mathrm{P}_{1} 2_{1} 2$. After translation searches with CNS program [33] according to these two rotation angles, the initial model of $A B$ - and $C D$-chains of agglutinin was established.

\section{Crystallographic Refinement}

Structural refinement were performed in the following iteration steps: rigid body refinement [34], simulated annealing [35] of residue coordinates, group B factor refinement [34], density modification [36], manual manipulation using O program [37], and energy minimization [38]. The crystal data and $\mathrm{R}$ factor are listed in Table 1 . The final $\mathrm{R}$ factor using all reflections in the resolution range 2.6 to $30 \AA$ is $20.4 \%$, while $R_{\text {free }}$ using randomly selected $10 \%$ reflections which were excluded from refinement is $23.6 \%$. The Ramachandran plot including A-, B-, C-, and D-chains is acceptable as shown in Table 1.

\section{Docking}

The program SPHGEN identifies the active site, and other sites of interest, and generates the sphere centers that fill the site. It has been described in the original paper [39]. The program GRID generates the scoring grids $[40,41]$. Within the DOCK suite of programs, the program DOCK matches spheres (generated by $\mathrm{SPH}-$ GEN) with ligand atoms and uses scoring grids (from GRID) to evaluate ligand orientations [38,39]. Program DOCK also minimizes energy based scores [42]. Parameters used in DOCK were modified from the paper of protein docking and complementary principle [43].

The atomic coordinates of the refined agglutinin structure and the reflection data have been deposited with the Protein Data Bank in Japan. The accession numbers for these atomic coordinates are (PDB ID) 2ZR1and (RCSB ID) RCSB028317.

\section{Results and Discussion}

As shown in figure 1, the AAG AB-chains are very similar to the abrin-a molecule, the structure of which has been described in detail [31]. A conserved disulfide bond between Cys246 of A (or C)-chain and Cys8 of B (or D)chain holds the two chains tightly as shown in figure 1.
Table 1: Crystal data and refinement statistics for AAG.

\begin{tabular}{|c|c|}
\hline Crystal ID & AAG \\
\hline Agglutinin A-Chain & Residues 1-250 \\
\hline Agglutinin B-Chain & Residues 5-267 \\
\hline Agglutinin C-Chain & Residues 1-250 \\
\hline Agglutinin D-Chain & Residues 5-267 \\
\hline X-ray wavelength $(\AA ̊)$ & 1 \\
\hline Crystal system & tetragonal \\
\hline Space group name & $\mathrm{P} 4,2,2$ \\
\hline Cell length a $(\AA ̊)$ & 137.050 \\
\hline Cell length b (Å) & 137.050 \\
\hline Cell length c $(\AA ̊)$ & 214.424 \\
\hline Cell volume $(\AA \AA \wedge 3)$ & 4027462.2 \\
\hline Cell formula units $Z$ & 16 \\
\hline $\begin{array}{l}\text { Cell measurement } \\
\text { temperature }(\mathrm{K})\end{array}$ & 100 \\
\hline Crystal shape & octahedron \\
\hline Crystal color & transparent \\
\hline Crystal size $\left(\mathrm{mm}^{\wedge} \wedge\right)$ & $0.30 \times 0.30 \times 0.25$ \\
\hline Colvent content (\%) & 72.33 \\
\hline $\begin{array}{l}\text { Matthews coefficient } \\
(\AA \wedge / \mathrm{Da})\end{array}$ & 4.45 \\
\hline Unique reflections & 73976 \\
\hline Averaged R_sym (outer sell) & $0.0727(0.3600)$ \\
\hline Averaged I/FI (outer sell) & $11.9(1.8)$ \\
\hline Completeness (\%) (outer sell) & $99.1(98.1)$ \\
\hline
\end{tabular}


Table 1: Crystal data and refinement statistics for AAG.

\begin{tabular}{|c|c|}
\hline Redundancy (outer sell) & $4.1(3.6)$ \\
\hline $\begin{array}{l}\text { Resolution range of } \\
\text { collection }(\AA)\end{array}$ & $2.47 \sim 30.0$ \\
\hline $\begin{array}{l}\text { Resolution range of } \\
\text { refinement }(\AA)\end{array}$ & $2.6 \sim 19.88$ \\
\hline R_cryst (outer sell) & $0.204(0.211)$ \\
\hline R_free (outer sell) & $0.236(0.256)$ \\
\hline No. of protein atoms & 8062 \\
\hline No. of water molecules & 169 \\
\hline No. of NAG atoms & 42 \\
\hline $\begin{array}{l}\text { rms deviation from ideal } \\
\text { bond length }(\AA)\end{array}$ & 0.009 \\
\hline $\begin{array}{l}\text { rms deviation from ideal } \\
\text { bond angle }\left(^{\circ}\right)\end{array}$ & 1.3 \\
\hline $\begin{array}{l}\text { Isotropic thermal factor } \\
\text { restraints }\end{array}$ & rms sigma \\
\hline $\begin{array}{l}\text { Main chain } \\
\text { bond }(\AA \wedge 2)\end{array}$ & $1.87 ; 1.50$ \\
\hline $\begin{array}{l}\text { Main chain } \\
\text { angle }(\AA \wedge 2)\end{array}$ & $2.84 ; 2.00$ \\
\hline Side chain bond $(\AA \AA \wedge 2)$ & $2.87 ; 2.00$ \\
\hline $\begin{array}{l}\text { Side chain } \\
\text { angle }(\AA \wedge 2)\end{array}$ & $3.90 ; 2.50$ \\
\hline
\end{tabular}

Ramachandran plot [50] (\%

of residues)

$$
\text { in the most favored } \quad 81.7
$$$$
\text { regions }(A, B, L)
$$

in the additionally $\quad 18.3 \%$

allowed regions

$(a, b, l, p)$
An asymmetric unit of AAG crystal contains four peptide chains, AB- and non-crystallographical-symmetric related $C D$-chains, as shown in figure 1 . The two heterodimers $\mathrm{AB}$ and $\mathrm{CD}$ are bonded together through hydrogen bonds by using the water molecules between them as intermediate bridges. They are identical except two N-acetylglucosamines (NAGs) are found in ABchains, and one in CD-chains. An AAG molecule is a tetramer, consisting of $\mathrm{AB}$ (or $\mathrm{CD}$ ) and symmetry-related $\mathrm{A}^{\prime} \mathrm{B}$ ' (or $\mathrm{C}^{\prime} \mathrm{D}^{\prime}$ ).

\section{Structure of the AAG A(or C)-chain}

The AAG A(or C)-chain was divided into three folding domains $\gamma 1, \gamma 2$, and $\gamma 3$ by reference to the description of the abrin-a A-chain [31], and to the CATH database [44]. Figure 2 shows the sequence and secondary structures, while figure 3 shows the cartoon of the three domains. Domain $\gamma 1$ (figure $3(\mathrm{a})$ ), composed of residues 1 to 111 , consists of two $\beta$-sheets and two $\alpha$-helices. The former $\beta$ sheets include six strands of adefgh (sheet 1) and two strands of bc (sheet 2), while the latter $\alpha$-helices include helix A of residues 13 to 27, and helix B of residues 91 to 96. The strands and helices alternate in the order aAbcdefgBh. In sheet 1 , the first strand, a, of the $\beta$-sheet 1 and the last strand, $h$, lie parallel to the neighboring strands, $d$ and $g$, respectively. The four central strands of the $\beta$ sheet $1, d$ to $g$, are anti-parallel. In sheet 2 , strands b and $c$ are anti-parallel. The main differences between domains $\gamma 1$ of AAG and abrin-a occurred in N-terminal. The Nterminal of the AAG A-chain is one residue shorter than that of the abrin-a A-chain and the first five terminal residues are different. Domain $\gamma 2$, residues 112 to 195 , is dominated by five helices (figure 3(b)), C to G. Helix C, composed of residues 112 to $119, \mathrm{D}$, residues 120 to 141 , E, residues 147 to $166, F$, residues 168 to 180 , and G, residues 188 to 194 . Helix $C$ is 3 residues longer than that of abrin-a, due to replacement of Thr114 and Arg118 in abrin-a by Asp113 and Lys117 in AAG. Other secondary structures in domain 2 are almost conserved in abrin-a and AAG. Domain $\gamma 3$ (figure 3(c)), composed of residues 198 to 250, contains two helices, H, residues 197 to 206 and I, residues 234 to 238 , and a $\beta$-sheet of two anti-parallel strands, $i$ and $j$, situated in the order HijI, and a random coil in the $\mathrm{C}$ terminal part. The last 8 residues in the $\mathrm{C}$ terminal of A-chain are severely disordered, and we could not determine their structures by X-ray diffraction.

\section{Structure of the AAG B (or D)-chain}

The overall folding of the AAG B (or D)-chain and the abrin-a B-chain is very similar, as shown in figure 1 , and the disulfide bond connecting A- and B-chains is conserved. The $\alpha$-carbon traces of their $\mathrm{N}$ terminal, residues 1 to 12 differ significantly. The first four residues in the 


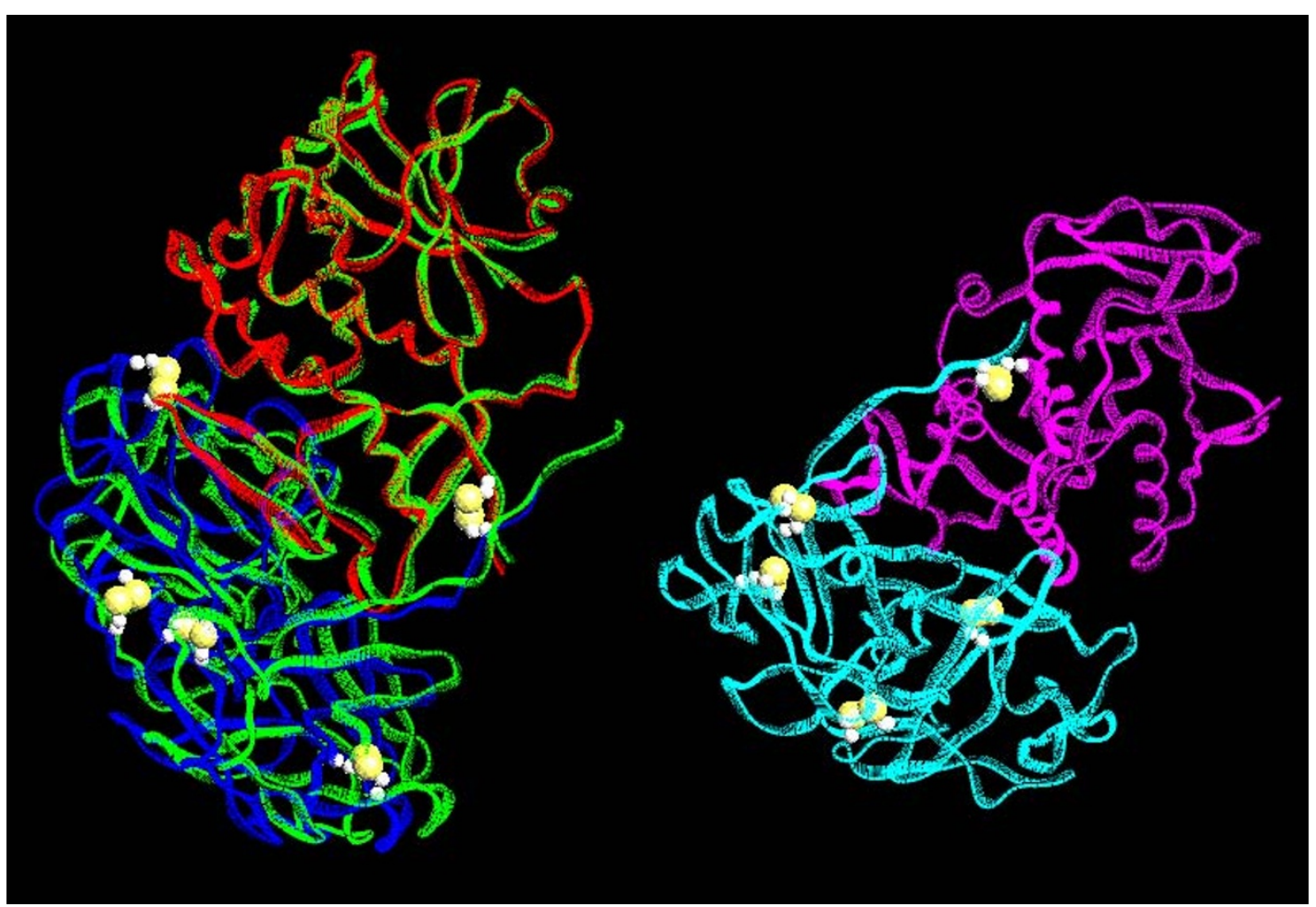

Figure 1 Comparison of AAG with abrin-a (green) molecule. The a-carbon backbone of abrin-a AB-chains are superimposed on that of the AAG molecule using least-squares analysis. A P4,2,2 asymmetric unit of AAG contains an AB-chain and a CD-chain. Disulphide bonds are plotted as big yellow balls. This figure was generated by O program (Jones et al., 1991).

VSIELG IDLTNAYVVAYRAGSESFF FRNAPASASTYLFTGTQQYSLPFDGNYDDLEK WAH

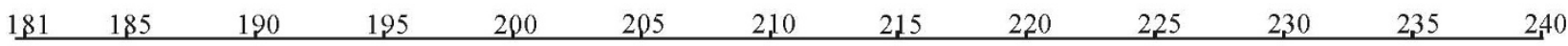

RAAFQDPPSM I SLENTWEPLSRAVQHTVQDTFPQNVTL I NVRQERVVVSSLSHPSVSALA กันกนกน 几n-

$241 \quad 245 \quad 250 \quad 258$

LMLF VCNPLNATQSPLL I

Figure 2 AAG A (or C)-chain sequence \& secondary structures. The symbol of "arrow" represents a $\beta$-strand, "spiral" represents an a-helix, "dot" represents missing residues, and the alphabets $a, b$, A, etc, denote the corresponding secondary structures in figure 3 . 


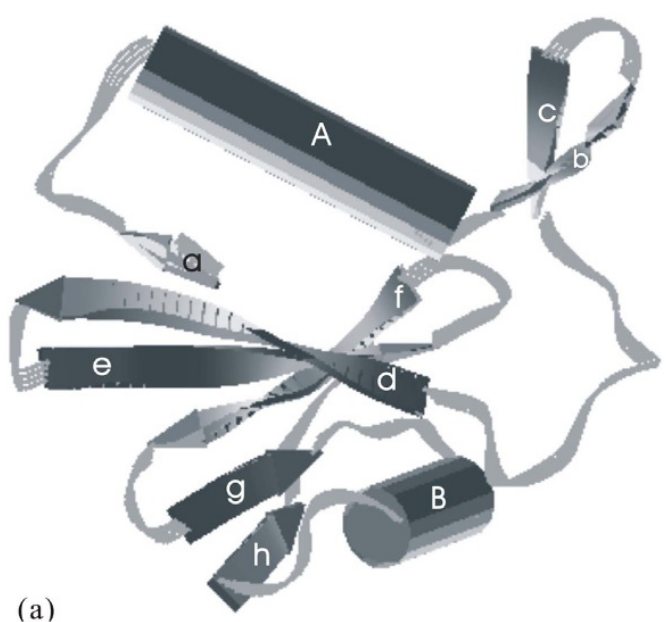

(a)

(b)

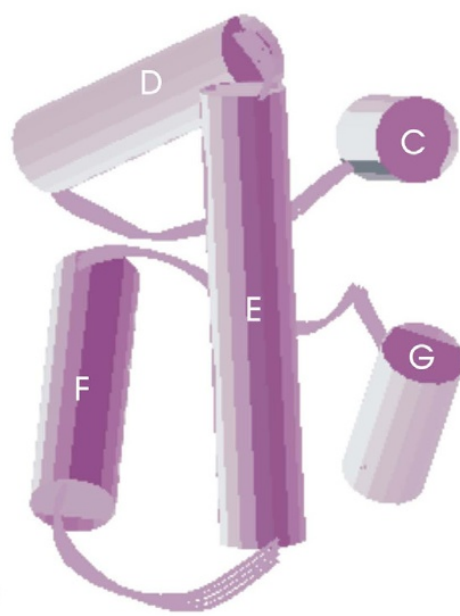

(c)

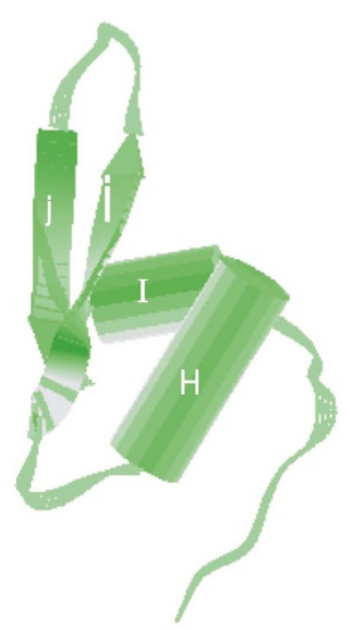

Figure 3 Three domains of AAG A (or C)-chain: (a) domain $\mathbf{\gamma}$ 1, (b) domain $\mathbf{2}$, (c) domain $\mathbf{\gamma}$ 3. These figures were generated by $O$ program (Jones et al., 1991). 


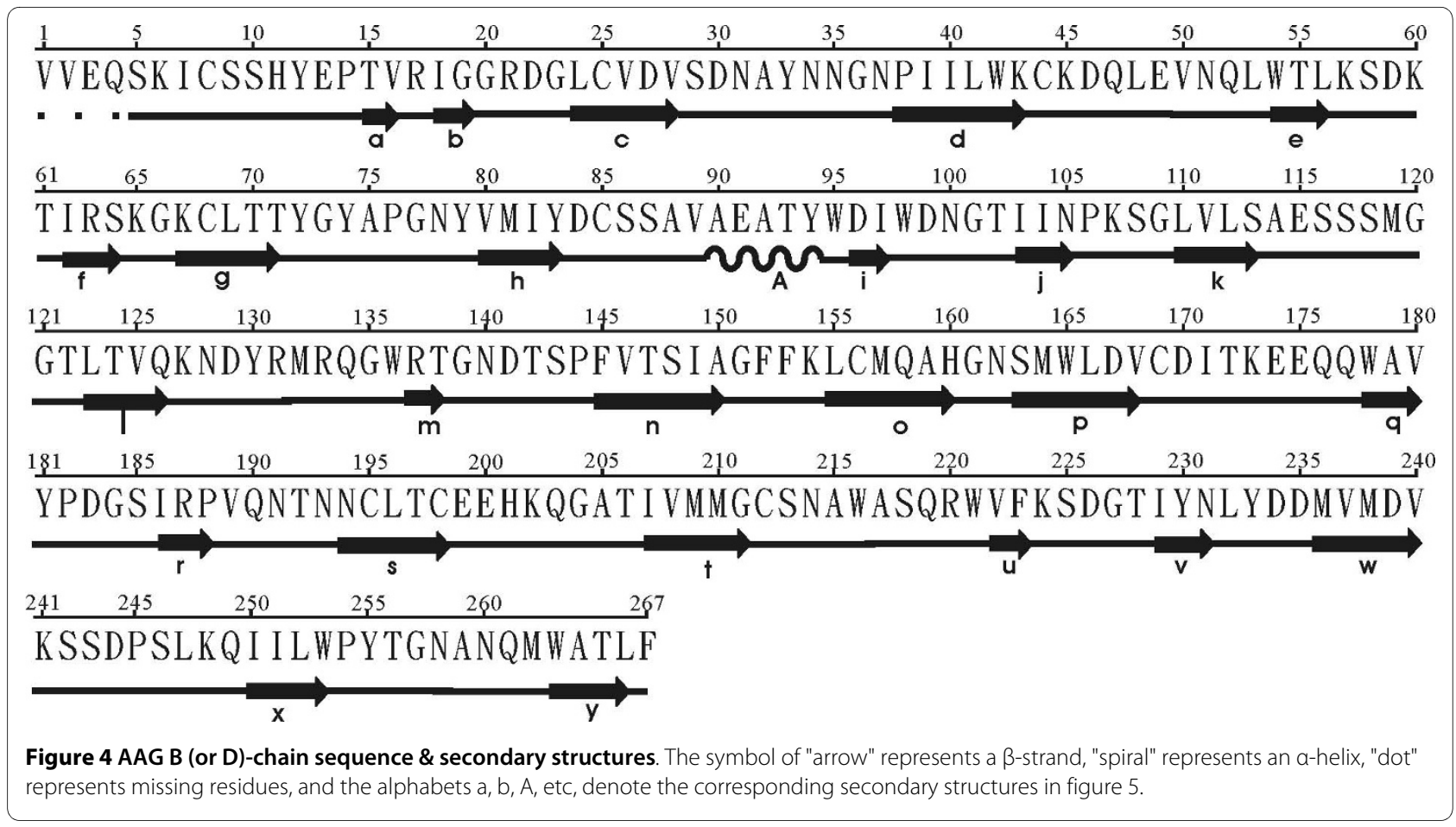

AAG B (or D)-chain are severely disordered, and we could not determine their structures by X-ray diffraction. The AAG B-chain is composed of two homologous domains, $\delta 1$ and $\delta 2$, mainly formed by $\beta$-sheets and loops. Figure 4 shows the sequence and secondary structures, while figure 5 shows the cartoon of the two domains. Domain $\delta 1$ (figure $5(\mathrm{a})$ ), composed of residues 5 to 140 , consists of five anti-parallel $\beta$-sheets, one 4stranded (of ijkl), one 3-stranded (of aef), and three 2stranded (strands bm, cd, and gh respectively), and one $\alpha-$ helix of residues 90 to 94 . The strands and helices alternate in the order abcdefghAijklm. Domain $\delta 2$ (figure 5(b)), composed of residues 141 to 267 , consists of four anti-parallel $\beta$-sheets, including two 4-stranded (strands ynqr and uvwx respectively), and two 2 -stranded (strands op and st) sheets.

Each domain of $\delta 1$ and $\delta 2$ contains two intra-domain disulfide bonds (Cys25-Cys44, Cys68-Cys85, Cys156-169, and Cys195-Cys212), which are conserved in abrin-a. Two NAGs are found in B-chain, but only one presents in D chain. The NAGs are bound to B-Asn100 (figure. 6), BAsn140, and D-Asn140 respectively. The bond length between NAG and Asn140 is $1.45 \AA$.

\section{Structure of Active site}

The active site is exactly the cleft formed by the intersection of all 3 domains in AAG A (or C)-chain. The location of the active site region of the AAG A (or C)-chain is shown in figure $7(\mathrm{a})$, and enlarged in figure $7(\mathrm{~b})$. Five invariant residues (Tyr73, Tyr112, Glu163, Arg166 and
Trp197) and five conserved residues (Asn71, Arg123, Gln159, Glu194 and Asn195) are located in the active site cleft. The alignment of the amino acid sequences shows that all five invariant residues in the active site of abrin-a are absolutely conserved throughout the wide range of ribosome-inactivating proteins $[19,45]$. The similarity of active site structures between abrin-a and AAG shows in figure 7 (b) that they may work in the same way, but could not explain the less than half biochemical activity of AAG. We try to answer this question by the 28SRNA docking study.

\section{Quaternary Structure of AAG}

An AAG molecule is a hetero-tetramer (as shown in figure 8) contains two subunits, $A B A^{\prime} B^{\prime}$ (or $C D C^{\prime} D^{\prime}$ ), stabilized by mainly hydrophilic and little hydrophobic forces. The two subunits are in equivalent positions of the space group $\mathrm{P}_{1}{ }_{2} 2$ 2. The transformation from $A B$ to $A^{\prime} B^{\prime}$ is $(x, y$, $\mathrm{z})$ to $(1-\mathrm{y}, 1-\mathrm{x}, 0.5-\mathrm{z})$, while $C D$ to $\mathrm{C}^{\prime} \mathrm{D}^{\prime}$ is $(\mathrm{x}, \mathrm{y}, \mathrm{z})$ to $(\mathrm{y}, \mathrm{x}$, $1-z)$. The hydrophilic interaction is dominated by intersubunit hydrogen bonds, as listed in table 2 . These hydrogen bonds belong to residues of domains $\gamma 2$ and $\gamma 2$ '. Since the $\gamma 2$ domain is almost made up with $\alpha$-helices, which hydrophobic side-chains are buried inside, hydrophobic forces contribute little to the stabilization of quaternary structure of AAG. The total buried surface area is 9360 for $A B A^{\prime} B^{\prime}$ and 9460 for $C D C^{\prime} D^{\prime}$ interfaces. The gain in hydrophobic energy is $-68 \mathrm{KCal} / \mathrm{Mol}$ for $\mathrm{ABA}^{\prime} \mathrm{B}^{\prime}$ and -72 $\mathrm{KCal} / \mathrm{Mol}$ for CDC'D'. The buried surface and hydrophobic energy are calculated by Protein interfaces, surfaces 
(a)

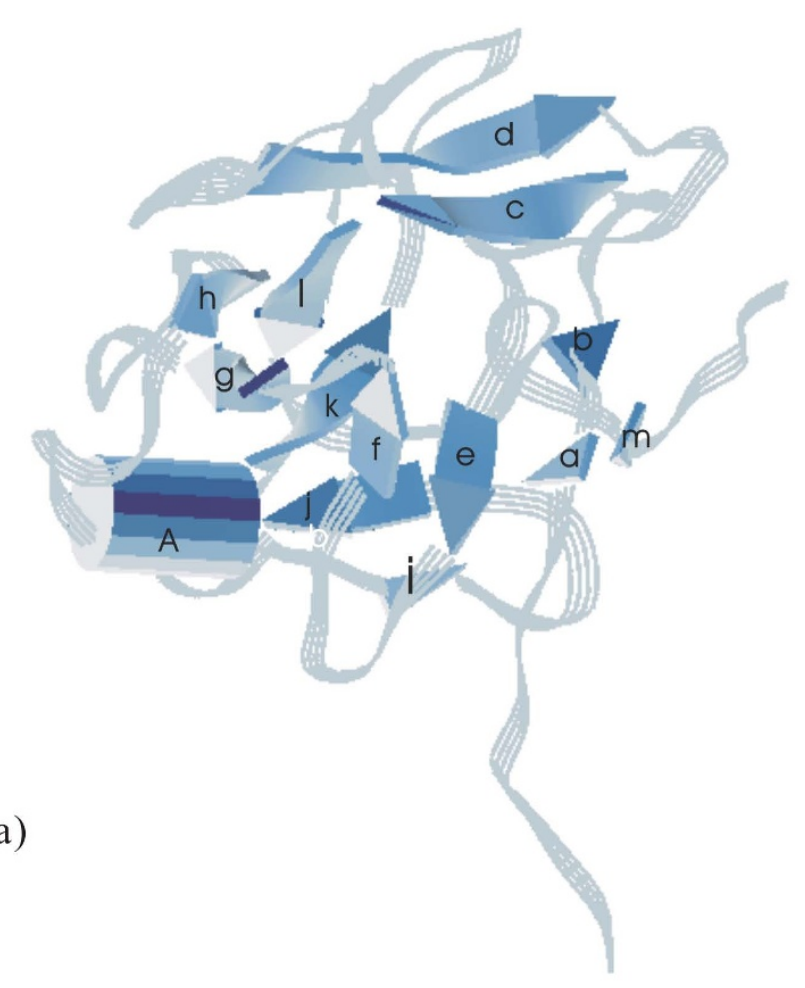

(b)

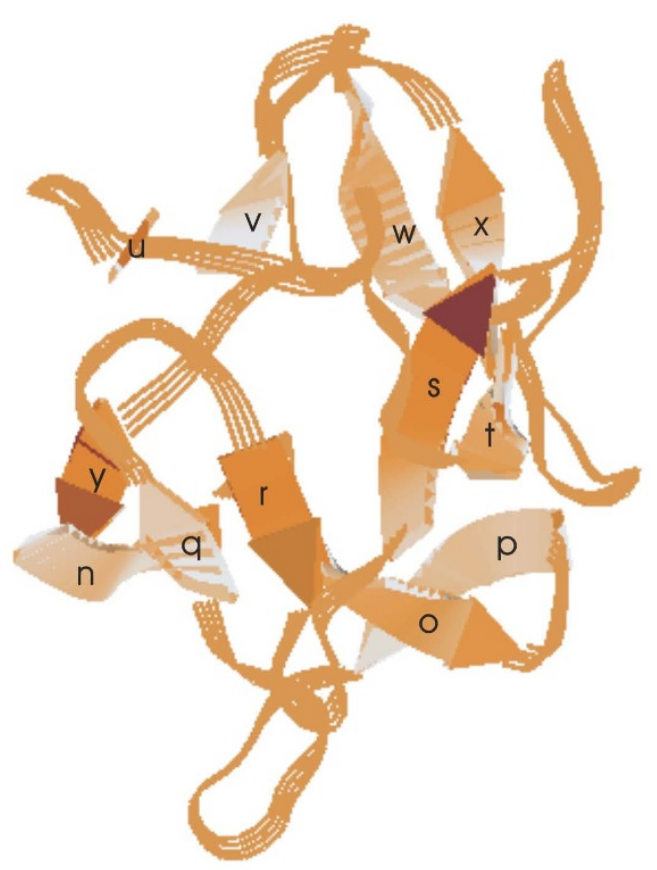

Figure 5 Two domains of AAG B (or D)-chain: (a) domain $\mathbf{\delta 1}$, and (b) domain $\mathbf{\delta 2}$. These figures were generated by O program (Jones et al., 1991). 

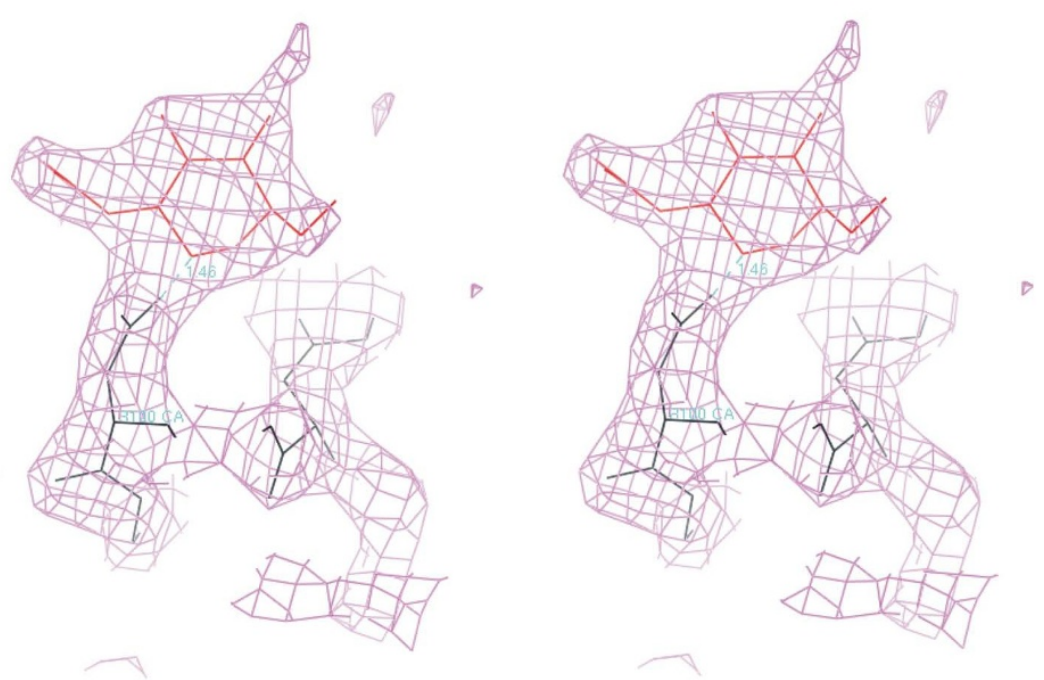

Figure 6 Electron density of the NAG (red) near B 100Asn using the (2Fo - Fc) map contoured at 2.0 F. This figure was generated by O program (Jones et al., 1991).
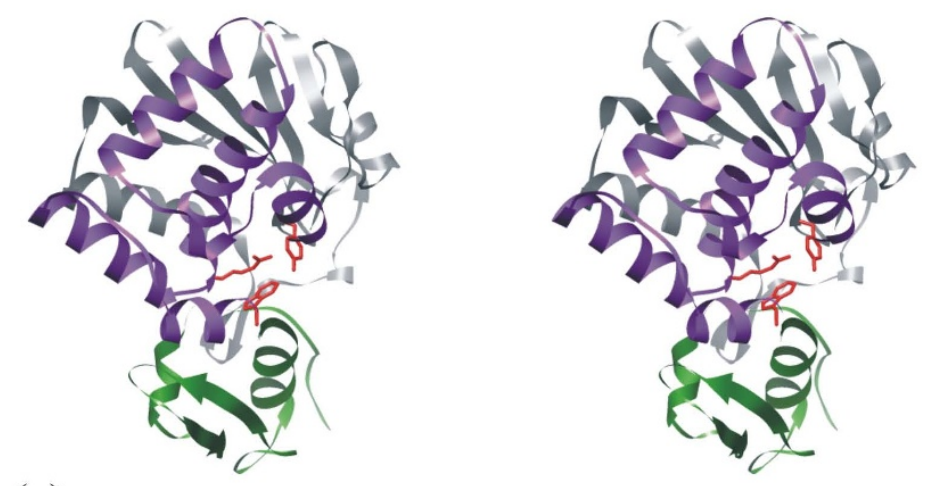

(a)
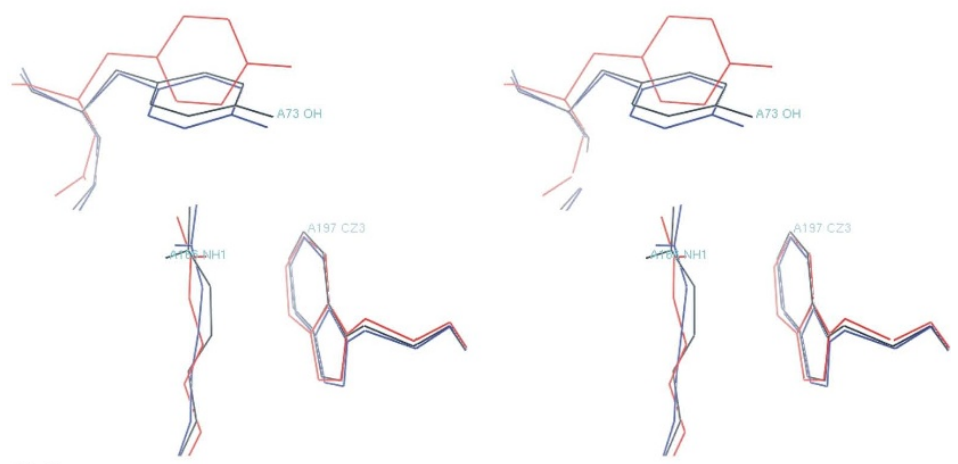

(b)

Figure 7 Three domains of AAG A (or C)-chain are drawn as ribbons. (a) Gray purple and green indicate domain $\gamma 1$ and green indicate domain $\gamma_{1} \gamma 2 \gamma 2$ and $\gamma 3$ respectively. Active site residues are drawn in red. (b) Active Site comparison of abrin-a (red) and $\gamma 3$ respectively. Active site residues are drawn in red. (b) Active Site comparison of abrin-a (red) AAG A-chain (black) AAG A-chain (black) and AAG C-chain (blue). These figures were generated by O program (Jones et al. and AAG C-chain (blue). These figures were generated by O program (Jones et al. 1991) and UCSF Chimera [32]. 


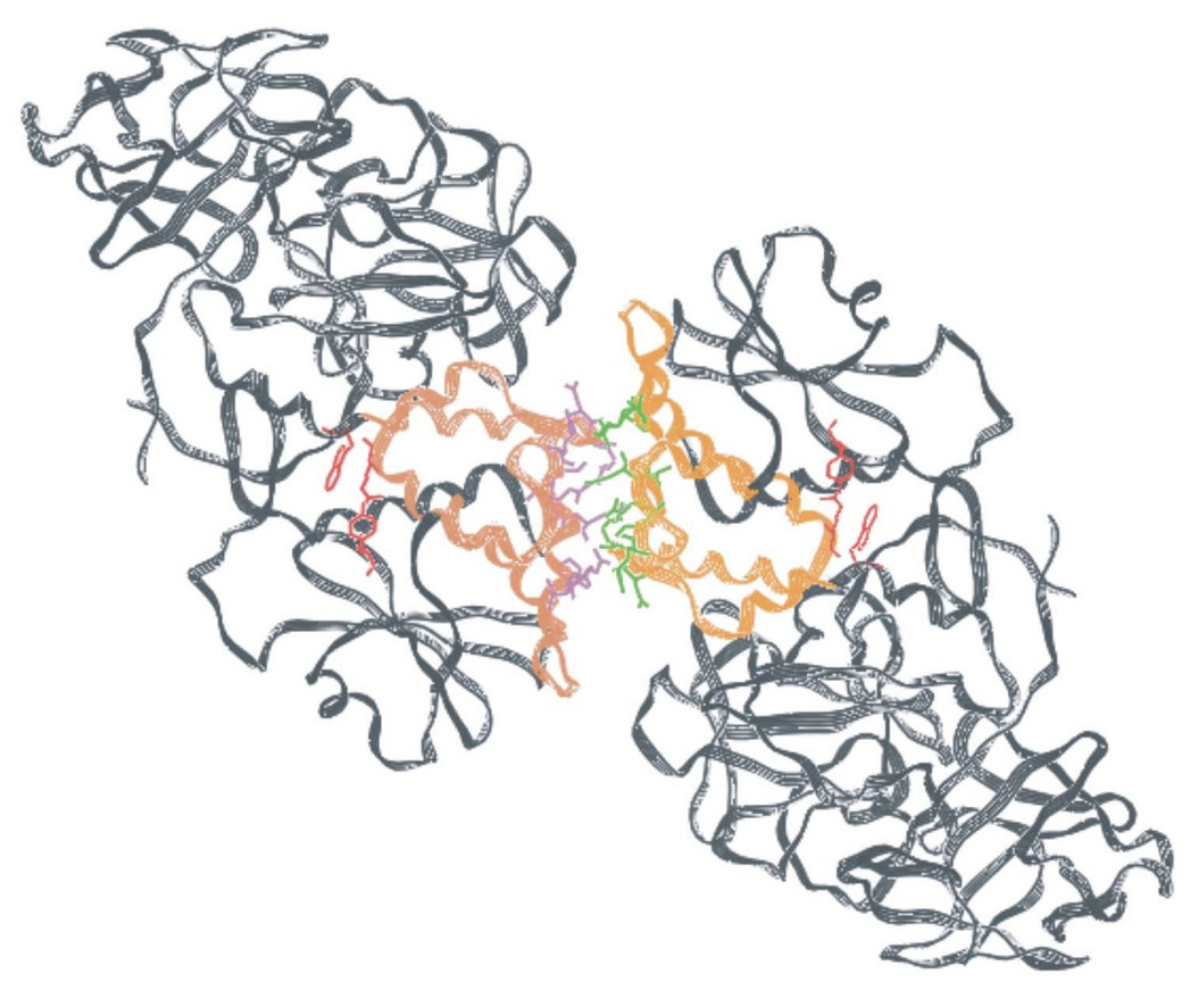

Figure 8 Ribbon presentation of AAG quaternary structure: Red residues indicate the active site location. Purple and green residues constitute inter-subunit hydrogen bonds. Domain Y2s are drawn in brown. This figure was generated by O program (Jones et al., 1991).

Table 2: Hydrogen bonds between inter-subunit with symmetry-related AA' and CC' chains.

\begin{tabular}{llllll}
\hline Donor & Acceptor & D....A (A) & Donor & Acceptor & D....A (A) \\
\hline A Gln 121 NE2 & A'Gln121 OE1 & 2.85 & A Gln121 NE2 & A'Gln121 OE1 & 2.85 \\
\hline A Arg 25 NH1 & A'Glu148OE2 & 2.77 & A Arg125NH1 & A'Glu148OE2 & 2.77 \\
\hline A Leu 130 N & A'Glu1310E2 & 3.15 & A Leu 130 N & A'Glu131OE2 & 3.15 \\
\hline A Arg 134 NH2 & A'Asn 180 O & 2.86 & A Arg 134 NH2 & A'Asn 180 O & 2.86 \\
\hline A Arg 134 NE & A'Asn 181 O & 3.06 & A Arg 134 NE & A'Asn 181 O & 3.06 \\
\hline A Gln 135 NE2 & A'Ser 127 OG & 3.07 & A Gln 135 NE2 & A'Ser 127 OG & 3.07 \\
\hline C Gln 121 NE2 & C'Ser 145 O & 2.75 & C Gln 121 NE2 & C'Ser 145 O & 2.75 \\
\hline C Ser 127 OG & C'Gly 143 N & 2.95 & C Ser 127 OG & C'Gly 143 N & 2.95 \\
\hline C Arg 134 NR & C'Tyr57 OH & 2.64 & C' Arg 134 NR & C Tyr57 OH & 2.64 \\
\hline C Gln 135 NE2 & C'Gln135 O & 2.94 & C' Gln 135 NE2 & C Gln135 O & 2.94 \\
\hline C Ser 145 N & C'Gln121OE1 & 2.59 & C' Ser 145 N & C Gln121 O & 2.59 \\
\hline
\end{tabular}




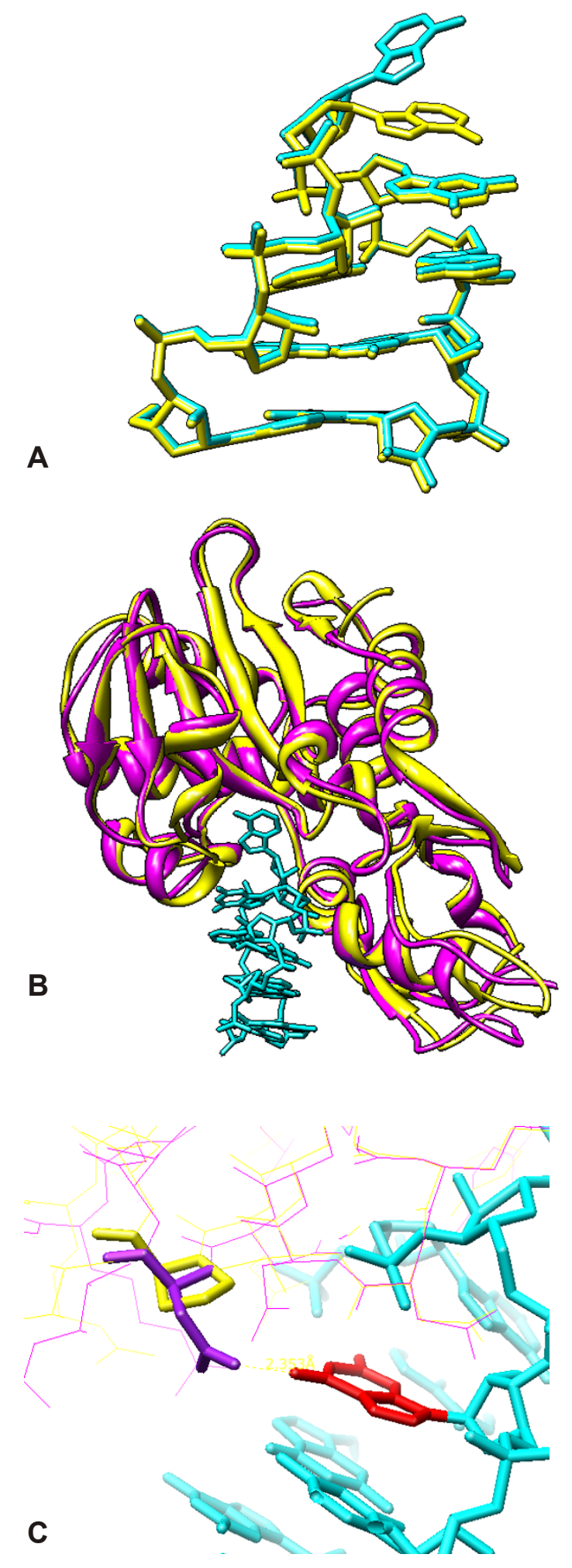

Figure 9 (a) The docking model (blue) and the original 28SRNA (yellow). A4324 was artificially manipulated. (b) The docking of 28SRNA (blue) on abrin-a A-chain (purple) and AAG A-chain (yellow). (c) G4323 (red) of 28SRNA docking model (blue), is hydrogen-bonded with Asn2000 of abrin-a Achain (purple), but has no interaction with corresponding Pro199 of AAG A-chain (yellow). 
and assemblies service PISA at European Bioinformatics Institute http://www.ebi.ac.uk/msd-srv/prot int/ pistart.html[46].

\section{Docking of 28SRNA to AAG and Abrin-a}

As pointed out in the mutagenesis study [21], Pro199 in A- (or C-) chain of AAG impair the activity of protein synthesis inhibition. Bagaria et al., [25] suggested that the less toxic nature is because of the fewer interactions involved with the substrate adenine. From our docking study, we found Asn200 of abrin-a may form a critical hydrogen bond with G4323 of 28SRNA, while corresponding Pro199 of agglutinin is a non-extended residue bound with the cleft in a more compact complementary relationship as shown in figure 9(c). This may explain the lower toxicity of agglutinin, despite of similarity in secondary structure and the activity cleft of two RIPs. The docking model of 28SRNA was artificially deformed at the ribose sugar of A4324 from the X-ray crystal structure 430D [47], as shown in figure 9(a), so that A4324 of 28SRNA can overlap with the adenine of the ricin-adenine complex, 1IFS [48]. Figure 9(b) shows deformed model fit well in the active clefts of both abrin-a and AAG. Figures 9(a), 9(b) and 9(c) were generated with UCSF Chimera [49].

We want to explore whether the difference in the critical residue, bring any change in structure. However, we could not observe significant main-chain distortion due to the difference in the 200 residue on higher resolution structure. Hence, the reason for the lower toxicity of agglutinin than abrin-a might be due to the deformation from inactive to active state of abrin depends on the meta-stable huge helix, composed of helix $\mathrm{h}$ and helix g. The mutation of Asn200 to Pro200 destroys the mechanism.

\section{Conclusion}

We have successfully solved the structure of $120 \mathrm{kDa}$ heterotetramer agglutinin $\mathrm{AB}$ and $\mathrm{CD}$ chains, and reduced the R-factor to $20.4 \%$ at $2.6 \AA$ resolution data. Ten disulfide bonds, three $\mathrm{N}$-acetylglucosamines, and 169 water molecules were found in the successive (2Fo- $\mathrm{Fc}$ ) map. 22 hydrogen bonds between A (or C)-chain and symmetryrelated $\mathrm{A}^{\prime}$ (or $\mathrm{C}^{\prime}$ ) were found. Water molecules were not found in the Bagaria's paper and no subsequent hydrogen bond lengths were listed based on their lower resolution structure [25]. Docking study revealed that due to Pro199, agglutinin is unable to form a critical hydrogen bond with G4323 of 28SRNA, which is found in the docking result of abrin-a. This may explain the lower toxicity of agglutinin than abrin-a, despite of similarity in secondary structure and the activity cleft of two RIPs.

\section{Abbreviations}

RIP: ribosome-inactivating protein; AAG: agglutinin; NAG: $\mathrm{N}$-acetylglucosamine; Fo: observed structure factor; Fc: calculated structure factor; PDB: protein data bank.

\section{Competing interests}

The authors declare that they have no competing interests.

\section{Authors' contributions}

JC collected the X-ray diffraction data, analyzed the crystal structure and prepared the initial manuscript. LTH set up the laboratory of the crystal structure determination, screened the crystallization conditions and got the right one, and advised such studies. LJY and LCL purified the material of the agglutinin.

\section{Acknowledgements}

The authors thank Mr Shyh-Ming Chen for setting up the computing programs. They also thank to the National Science Council of Taiwan for financial support. They are indebted to SPring-8 and the National Synchrotron Radiation Research Center for data collection.

\section{Author Details}

1Department of Physics, National Tsing Hua University, Hsinchu 30013, Taiwan, ${ }^{2}$ Graduate School of Biochemical Engineering, Ming Chi University of Technology, Taishan, Taipei, 24301, Taiwan and 3Institute of Biochemistry, College of Medicine, National Taiwan University, Taipei 10018, Taiwan

Received: 4 January 2010 Accepted: 30 April 2010

Published: 30 April 2010

\section{References}

1. Endo Y, Misui K, Motizuki K, Tsurugi $K$ : The mechanism of action of ricin and related toxic lectins on eukaryotic ribosomes. The site and the characteristics of the modification in $28 \mathrm{~S}$ ribosomal RNA caused by the toxins. J Biol Chem 1987, 262:5908-5912.

2. Endo $Y$, Tsurugi $K$ : RNA N-glycosidase activity of ricin A-chain Mechanism of action of the toxic lectin ricin on eukaryotic ribosomes. J Biol Chem 1987, 262:8128-8130.

3. Endo Y, Gluck A, Wool IG: Ribosomal RNA identity elements for ricin Achain recognition and catalysis. J Mol Biol 1991, 221:193-207.

4. Jimenez A, Vazquez DC: Plant and Fungal Protein and Glycoprotein Toxins Inhibiting Eukaryote Protein Synthesis. Annu Rev Microbiol 1985, 39:649-672.

5. Barbieri L, Stirpe F: Ribosome-inactivating proteins from plants: properties and possible uses. Cancer Surv 1982, 1:489-520.

6. Stirpe F, Barbieri L, Battelli MG, Soria M, Lappi DA: Ribosome-inactivating proteins leads to increased fungal protection in transgenic tobacco plants. Bio-Technology 1992, 10:405-412.

7. Hartley MR, Lord JM: Cytotoxic ribosome-inactivating lectins from plants. Biochim Biophys Acta 2004, 1701:1-14.

8. Olsnes S: The history of ricin abrin and related toxins. Toxicon 2004, 44:361-370.

9. Lin J, Chen Y, Xu Y, Yan F, Tang L, Chen F: Cloning and expression of curcin a ribosome inactivating protein from the seeds of jatropha curcas. Acta Botanica Sinica 2003, 45:858-863.

10. Mi SL, An CC, Wang Y, Chen JY, Che NY, Gao Y, Chen ZL: Trichomislin a novel ribosome-inactivating protein a novel ribosome-inactivating protein induces apoptosis that involves mitochondria and caspase-3. Archives of Biochemistry and Biophysics 2005, 434:258-265.

11. Olsnes S, Phil A: Different biological properties of the two constituent peptide chains of ricin a toxic protein inhibiting protein synthesis. Biochemistry 1973, 12:3121-3126.

12. Lin JY, Lee TC, Hsu ST, Tung TC: Isolation of four isotoxic proteins and one agglutinin from jequiriti bean (Abrus precatorius). Toxicon 1981, 19:41-51.

13. Lord JM: Synthesis and intracellular transport of lectin and storage protein precursors in endosperm from castor bean. Eur J Biochem 1985, 146:403-409.

14. Mundy J, Leah R, Boston R, Endo Y, Stirpe F: Genes encoding ribosomeinactivating proteins. Plant Mol Biol Rep 1994, 12:60-62. 
15. Leah R, Tommerup H, Svendsen I, Mundy J: Biochemical and molecular characterization of three barley seed proteins with antifungal properties. J Biol Chem 1991, 266:1564-1573.

16. Desvoyes B, Poyet JL, Schlick JL, Adami P, Jouvenot M, Dulieu P: Identification of a biological inactive complex form of pokeweed antiviral protein. FEBS Lett 1997, 410:303-308.

17. Olsnes S, Phil A: In Receptors and Recognition Series: The Specificity and Action of Animal. In Bacterial and Plant Toxins Edited by: Cuatrecasas P. Chapman and Hall, London; 1982:31-131.

18. Lin JY, Li JS, Tung TC: Lectin Derivatives of Methotrexate and Chlorambucil as Chemotherapeutic Agents. J Natl Cancer Inst 1981, 66:523-528

19. Funatsu G, Taguchi Y, Kamenosno M, Yanaka M: The complete amino acid sequence of the A-chain of abrin-a a toxic protein from the seeds of Abrus precatorius. Agric Biol Chem 1988, 52:1095-1097.

20. Chen YL, Chow LP, Tsugita A, Lin JY: The complete primary structure of abrin-a B chain. FEBS Lett 1992, 309:115-118.

21. Liu CL, Tsai CC, Lin SC, Wang LI, Hsu Cl, Hwang MJ, Lin JY: Primary Structure and Function Analysis of the Abrus precatorius Agglutinin A Chain by Site-directed Mutagenesis. J Biol Chem 2000, 275:1897-1901.

22. Hung CH, Lee MC, Lee TC, Lin JY: Primary Structure of Three Distinct Isoabrins Determined by CDNA Sequencing: Conservation and Significance. J Mol Biol 1993, 229:263-267.

23. Hung CH, Lee MC, Chen JK, Lin JY: Cloning and expression of three abrin A-chains and their mutants derived by site-specific mutagenesisin Escherichia coli. Eur J Biochem 1994, 219:83-87.

24. Chen JK, Hung CH, Liaw YC, Lin JY: Identification of amino acid residues of abrin-a A chain is essential for catalysis and reassociation with abrina B chain by site-directed mutagenesis. Protein Engineering 1997, 10:827-833

25. Bagaria A, Surendranath K, Ramagopal UA, Ramakumar S, Karande AA: Structure-Function Analysis and Insights into the Reduced Toxicity of Abrus precatorius Agglutinin I in Relation to Abrin. J Biol Chem 2006, 281:34465-34474

26. Panneerselvam K, Lin SC, Liu CL, Liaw YC, Lin JY, Lu TH: Crystallization of agglutinin from the seeds of Abrus precatorius. Acta Cryst 2000, D56:898-899

27. Smith PK, Krohn Rl, Hermanson GT, Mallia AK, Gartner FH, Provenzano MD, Fujimoto EK, Goeke NM, Olson BJ, Klenk DC: Measurement of protein using bicinchoninic acid. Anal Biochem 1985, 150:76-85.

28. McPherson A: Preparation and Analysis of Protein Crystals. John Wiley \& Sons John Wiley \& Sons New York USA; 1982:94-96. 115

29. Otwinowski Z, Minor W: Processing of X-ray Diffraction Data Collected in Oscillation Mode. Methods in Enzymology. Macromolecular Crystallography part A 1997, 276:307-326.

30. Brunger AT, Adams PD, Clore GM, Delano WL, Gros P, Grosse-Kunstleve RW, Jiang JS, Kuszewski J, Nilges M, Pannu NS, Read RJ, Rice LM, Simonson $T$, Warren GL: Crystallography \& NMR system: A new software system for macromolecular structure determination. Acta Cryst 1998, D54:905-921.

31. Tahirov TH, Lu TH, Liaw YC, Chen YL, Lin JY: Crystal Structure of Abrin-a at 2.14 D. J Mol Biol 1995, 250:354-367.

32. DeLano WL, Brunger AT: The Direct Rotation Function: Rotational Patterson Correlation Search Applied to Molecular Replacement. Acta Cryst 1995, D51:740-748.

33. Brunger AT: Extension of molecular replacement: A new search strategy based on Patterson correlation refinement. Acta Cryst 1990, A46:46-57.

34. Brunger AT: The Free R Value: a Novel Statistical Quantity for Assessing the Accuracy of Crystal Structures. Nature 1992, 355:472-474.

35. Brunger AT, Krukowski A, Erickson J: Slow-Cooling Protocols for Crystallographic Refinement by Simulated Annealing. Acta Cryst 1990, A46:585-593.

36. Abrahams JP, Leslie AG W: Methods used in the structure determination of bovine mitochondrial F1 ATPase. Acta Cryst 1996, D52:30-42.

37. Jones TA, Zou JY, Cowan SW, Kjeldgaard M: Improved methods for the building of protein models in electron density maps and the location of errors in these models. Acta Cryst 1991, A47:110-119.

38. Adams PD, Pannu NS, Read RJ, Brunger AT: Cross-validated Maximum Likelihood Enhances Crystallographic Simulated Annealing Refinement. Proc Natl Acad Sci USA 1997, 94:5018-5023.
39. Kuntz ID, Blaney JM, Oatley SJ, Langridge R, Ferrin TE: A geometric approach to macromolecule-ligand interactions. J Mol Biol 1982, 161:269-288.

40. Shoichet BK, Bodian DL, Kuntz ID: Molecular docking using shape descriptors. J Comp Chem 1992, 13:380-397.

41. Meng EC, Shoichet BK, Kuntz ID: Automated docking with grid-based energy evaluation. J Comp Chem 1992, 13:505-524.

42. Meng EC, Gschwend DA, Blaney JM, Kuntz ID: Orientational sampling and rigid-body minimization in molecular docking. Proteins 1993 17:266-278.

43. Shoichet BK, Kuntz ID: Protein docking and complementarity. J Mol Biol 1991, 221:327-346.

44. Pearl F, Todd A, Sillitoe I, Dibley M, Redfern O, Lewis T, Bennett C, Marsden R, Grant A, Lee D, Akpor A, Maibaum M, Harrison A, Dallman T, Reeves G, Diboun I, Addou S, Lise S, Johnston C, Sillero A, Thornton J, Orengo C: The CATH Domain Structure Database and related resources Gene3D and DHS provide comprehensive domain family information for genome analysis. Nucl Acids Res 2005:D247-D251.

45. Rutenber E, Robertus JD: Structure of ricin B-chain at $2.5 \AA$ A resolution. Proteins Struct Func Genet 1991, 10:260-269.

46. Krissinel $E$, Henrick $K$ : Inference of macromolecular assemblies from crystalline state. J Mol Biol 2007, 372:774-797.

47. Correll CC, Munishkin A, Chan YL, Ren Z, Wool IG, Steitz TA: Crystal structure of the ribosomal RNA domain essential for binding elongation factors. Proc Natl Acad Sci USA 1998, 95:13436-13441.

48. Weston SA, Tucker AD, Thatcher DR, Derbyshire DJ, Pauptit RA: X-ray structure of recombinant ricin A-chain at $1.8 \AA$ Å resolution. $J \mathrm{Mol}$ Bio 1994, 244:410-422.

49. Pettersen EF, Goddard TD, Huang CC, Couch GS, Greenblatt DM, Meng EC, Ferrin TE: UCSF Chimera - A Visualization System for Exploratory Research and Analysis. J Comput Chem 2004, 25:1605-1612.

50. Laskowski RA, MacArthur MW, Moss DS, Thornton JM: PROCHECK: a program to check the stereochemical quality of protein structures. $J$ App Cryst 1993, 26:283-291.

doi: $10.1186 / 1423-0127-17-34$

Cite this article as: Cheng et al., A biophysical elucidation for less toxicity of Agglutinin than Abrin-a from the Seeds of Abrus Precatorius in consequence of crystal structure Journal of Biomedical Science 2010, 17:34

\section{Submit your next manuscript to BioMed Centra and take full advantage of:}

- Convenient online submission

- Thorough peer review

- No space constraints or color figure charges

- Immediate publication on acceptance

- Inclusion in PubMed, CAS, Scopus and Google Scholar

- Research which is freely available for redistribution 